\title{
Survey of Annual Paid Leave Acquisition of Hospital Physicians in Japan (2015)
}

\author{
Go Igusa ${ }^{1}$ \\ ${ }^{1}$ School of Economics, Matsuyama University, Ehime, Japan \\ Correspondence: Go Igusa, School of Economics, Matsuyama University, Bunkyocho 4-2, Matsuyama, Ehime, Japan.
}

Received: October 5, 2015

doi:10.11114/ijsss.v3i6.1173
Accepted: October 19, 2015

Available online: October 27, 2015

\begin{abstract}
In this paper, we investigate about the reality of unacquired annual leave, which has become one of the main pillars of the working conditions of doctors, by conducting a questionnaire survey on hospital physicians, and investigate the disparity between different hospital departments and their work environment and the difference in the attitude of hospital physicians. This report summarizes the results of the survey.
\end{abstract}

Keywords: annual paid leave, doctors who work at hospitals, medical office, surgical departments, Labor Standards Law

\section{Introduction}

In Japan, exploiter "black" companies have become a major problem. "Black" company refers to the companies that impose a squalid working environment on the end employees in order to achieve their ultimate imperative of cost reduction. Also, in Japan's medical industry, there are end workers who have been forced to work in very poor working environments. Who would these people be? They are the doctors working in the hospitals, who are exploited with almost no resting time, until they are on the brink of death from overworking.

In addition, among the problems manifesting currently in the supply and demand, such as the uneven distribution of doctors, the improvement of working conditions of doctors and the rebuilding of the mechanism of supply-and-demand regulation, together with a comprehensive response from the labor policy point of view has become an urgent issue in order to meet the labor demand of doctors into the future, and in order to build and maintain a safe and secure health care provider system. In particular, it is needless to say that in order to eliminate the accumulated fatigue, it is necessary for doctors to obtain annual paid leave (annual leave), a "vacation" when they can get both spiritual and physical rest at a suitable time for them.

\section{Research Objectives}

The topic of the labor of physicians has attracted attention in recent years. However, there has been almost no sociological research or study on the annual leave acquisition of physicians. In recent years, among the sociological studies on the labor of doctors there have been a few, such as a study that focused on the way of working of female doctors (Boulis 2004, Boulis and Jacobs 2008, Nakamura 2010), and also a study on the types of employment of doctors and the internal structure of the industry (Nakano 1996), etc., but it can be said that there is almost no sociological research focused on annual leave acquisition and the working hours of doctors.

In this paper, we investigate about the reality of unacquired annual leave, which has become one of the main pillars of the working conditions of doctors, by conducting a questionnaire survey on hospital physicians, and investigate the disparity between different hospital departments and their work environment and the difference in the attitude of hospital physicians. This report summarizes the results of the survey (The quantitative analysis of the survey results is carried out in another paper).

It should be noted that the present study is a part of the research results by the Matsuyama University special research grant received for the 2015 fiscal year. The paper on the survey results are to be used as basic data for quantitative analysis for future policymaking. 


\section{Research methods and the subjects of the research}

The survey was carried out via the Internet with doctors who work in Japan's national hospitals (directors of clinics and hospitals are excluded) as subjects, from the medical system monitor owned by a private research firm (Rakuten Research Corporation). We used random sampling. (Note 1) The distribution amount was determined so that we can collect 800-1000 samples.

\section{Method of implementation}

This survey was carried out on doctors who work at hospitals. However, since at the time of the survey in the doctor's registration monitor of Rakuten Research Corporation there was no distinction between full-time or part-time employees, a screening was carried to determine whether the subject was a full-time worker or not. The question of the screening is as follows. (Note 2)

SC2 Please let us know your employment type at your main workplace.

1. Full-time

2. Part-time

3. Side-job

Regarding the above question, people who answered 2 and 3 were screened out, only the people who selected "1", the full-time hospital physicians were selected as subjects for the survey.

\section{The schedule of the implementation of the survey and valid response rate}

The survey period was 7 days between June 19 to June 25, 2015.

The distribution amount was a 63,299, screening response number was 6,877 (incidence rate: $10.9 \%$ ), current survey collection had 1,682 responses (response rate 24.5\%). Then, 800 responses were delivered from Rakuten Research Corporation excluding invalid responses, and these were subjected to analysis. The valid response rate was $47.6 \%$. (Note 3) (Note 4)

\section{The number of annual leave days taken differentiated by the attributes and working styles of the respondent}

\subsection{The number of annual leave days taken by the respondent}

In Table 1, we will first take a look at the actual number of annual leave days taken in the period of one year last year at the main workplace. The average number of annual leave days taken by the respondents is 5.8 days and the breakdown is as follows: the highest percentage is "0 days" with $24.5 \%$, followed by "7 to 10 days" (23.8 percent), "4 to 6 days" (22.5\%), and "1 to 3 days" (16.3\%), over 40\% (40.8\%) have answered with "3 days or less" (the sum of responses from "0 days" and "1 to 3 days"). Those who responded with "11 days or more" (the sum of "11 to 15 days", "16 to 19 days", "20 days or more") is $13.0 \%$, those who responded with "16 days or more" ( the sum of "16 to 19 days" and "20 days or more."), is 5.9\%. People who got "20 days or more" of annual leave is $4.9 \%$ of the total (Figure 1).

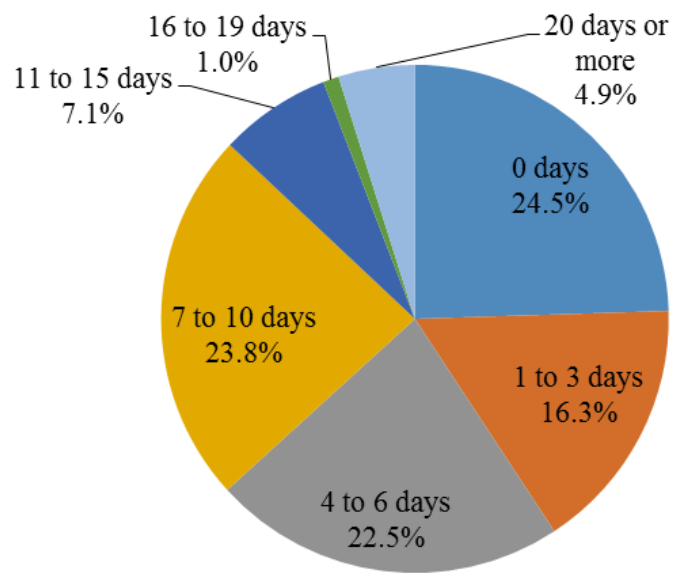

Fig. 1. Number of annual leave days taken by doctors

\subsection{The average number of annual paid leave days as seen by individual attributes}

Looking at the number of annual paid leave days by gender, females have taken 0.1 days more than males. In terms of age, the number of annual leave days increases with age until the age of 50's, on the other hand, as the age exceeds the 60 's, the number of leave days decreases. In terms of marital status, the married have taken 1.3 days more in comparison 
to the unmarried. In terms of the having children or not, those who have children have taken 1.1 days more than those who do not.

In terms of university they graduated from, the number of annual leave days take is slightly more in the case of graduates from lower ranked private universities compared to public universities or high ranked private university graduates. (Note 5) When looking at differences between doctors who belong to a medical office, we see that they take 0.5 days fewer annual leave days than the doctors who do not belong to a medical office.

In terms of years of experience as a doctor, those who have "more than 1 year and less than 3 years" experience take the most days with 6.5 days followed by those with "more than 15 years" experience ( 6.0 days), those with "more than 10 years and less than 15 years" (5.5 days), those with "more than 3 years and less than 5 years "(5.4 days) and such, we can see that there is no particular tendency observed. In terms of positions, while those who have the position of "assistant professor" or lower rank take 5.5 days or less, those in the position of "head physician, lecturer, head of medical office" or above take 5.6 days or more, therefore we can observe that the higher their position, the more leave days they take.

There are items in common with the findings of "Survey on the acquisition of annual paid leave" (2011) by the Japan Institute for Labor Policy and Training regarding the general workers of Japan, for example that women take more days off than men, those with children take more days off than those who do not have children, etc., there is a certain uniformity in the trends when comparing the results of this survey conducted on physicians.

\subsection{The number of annual leave days taken as seen from different departments}

Looking at the actual number of annual leave days taken in the period of one year last year at the main workplace in different departments, we can see that the most leave days, 7.7 days are take in the pulmonology department, followed by dermatology and the emergency department ( 7.3 days), pediatrics ( 7.1 days), and ophthalmology ( 7.0 days). The departments where the number of days of annual leave taken is less is obstetrics-gynecology (3.0 days), neurosurgery (4.1 days), gastroenterology (4.3 days) and the surgical department (4.7 days). The number of days taken for annual leave is even smaller for members of a specialized surgical department.

\subsection{The number of annual leave days taken as seen from annual income and average working hours}

Looking at the working hours per week including other workplaces, we can observe that even if there is a little variance, the longer the working time, the less the number of days of annual leave. This shows almost the same tendency if we look at the working hours per week at the main workplace.

In terms of annual income, including other workplaces, the most leave days, 7.0 days are taken by those who earn "1-3 million yen", followed by those who earn "20 million yen or more" (6.5 days), "15-20 million yen" (5.9 days), "5 million-7 million yen", "10-15 million yen" (5.4 days), there is no particular tendency. On the other hand, looking at the annual income at the main workplace, the higher the annual income, the more days of leave are taken.

\subsection{The number of annual leave days taken as seen from different forms of management}

In terms of management form of the main workplace, there was no big difference in the trends of annual paid leave days taken between "medical corporations", "educational institutions" or other public institutions, but in the case of respondents whose workplace is the university they graduated from, they take less days of leave than those who are not employed at the university where they graduated. Especially in the case of national university corporations, in cases where the employer is the national university corporation of the university they graduated from, they take 3.4 days less annual leave, than those employed by a national university corporation that is not the university they graduated from.

Looking at whether the main workplace is an acute care hospital or an emergency hospital, we can see that the most days taken off are in the case when the workplace is "neither" an acute care hospital nor an emergency hospital. In terms of location of the main workplace hospital, there was no particular difference observed. In terms of the scale of number of hospital beds in the main workplace, the most number of days taken was 6.6 days in the case of those working in a hospital with "49 beds or less", followed by "500-999 beds" (6.0 days), then "300-499 beds "(5.8 days) and so on, there is no tendency observed.

\subsection{The number of annual leave days taken as seen from different methods of taking leave}

First, by dividing the methods of taking annual leave at the main workplace into two categories based on the presence or absence of a substitute when taking the annual leave, we can observe that the number of days of leave taken is larger in the case when there is a substitute person (the total average of the work sharing method, circulating method, reverse circulating method is 6.0 days) compared to when there is no substitute person while taking annual leave (the total average of self-pay system (preceding), self-pay system (at a later date), the self-pay system (home-work) is 5.5 days). Then, when viewed on an individual level regarding the methods of taking leave, the most days, 6.2 days are taken by 
those with the "self-pay system (preceding)", followed by those with "work sharing method", and "reverse circulating method" (6.0 days ), and the "circulating method" (5.9 days).

Table 1. Simple totaling results of the number of annual leave days taken by doctors

\begin{tabular}{|c|c|c|c|c|}
\hline & & $\mathrm{n}$ value & $\%$ & $\begin{array}{c}\text { Mean value of the } \\
\text { number of annual } \\
\text { leave days taken }\end{array}$ \\
\hline & total & 800 & 100.0 & 5.8 \\
\hline \multirow{2}{*}{ Gender } & Male & 709 & 88.6 & 5.8 \\
\hline & Female & 91 & 11.4 & 5.9 \\
\hline \multirow{6}{*}{ Age } & $20^{\prime} \mathrm{s}$ & 13 & 1.6 & 5.0 \\
\hline & 30 s & 138 & 17.3 & 5.1 \\
\hline & $40^{\prime} \mathrm{s}$ & 265 & 33.1 & 5.5 \\
\hline & 50 s & 317 & 39.6 & 6.4 \\
\hline & $60^{\prime} \mathrm{s}$ & 66 & 8.3 & 6.0 \\
\hline & $70^{\prime} \mathrm{s}$ & 1 & 0.1 & 5.0 \\
\hline \multirow{3}{*}{ Married status } & Unmarried & 103 & 12.9 & 4.7 \\
\hline & Married & 668 & 83.5 & 6.0 \\
\hline & Divorced or widowed & 29 & 3.6 & 6.6 \\
\hline \multirow{2}{*}{ Children } & Have & 608 & 76.0 & 6.1 \\
\hline & Do not have & 192 & 24.0 & 5.0 \\
\hline \multirow{4}{*}{ Graduated university } & High ranked public university & 316 & 39.5 & 5.8 \\
\hline & Low ranked public university & 277 & 34.6 & 5.8 \\
\hline & High ranked private university & 119 & 14.9 & 5.7 \\
\hline & Low ranked private university & 88 & 11.0 & 6.1 \\
\hline \multirow{2}{*}{$\begin{array}{l}\text { Do you belong to a medical } \\
\text { office? }\end{array}$} & Yes & 446 & 55.8 & 5.6 \\
\hline & No & 354 & 44.3 & 6.1 \\
\hline \multirow{7}{*}{ Last year's annual income (all) } & between 1-3 million yen & 6 & 0.8 & 7.0 \\
\hline & between 3-5 million yen & 14 & 1.8 & 5.1 \\
\hline & between $5-7$ million yen & 23 & 2.9 & 5.4 \\
\hline & between $7-10$ million yen & 59 & 7.4 & 4.9 \\
\hline & between $10-15$ million yen & 212 & 26.5 & 5.4 \\
\hline & between $15-20$ million yen & 282 & 35.3 & 5.9 \\
\hline & 20 million yen or more & 204 & 25.5 & 6.5 \\
\hline \multirow{7}{*}{ Working hours per week (all) } & less than $20 \mathrm{hrs}$ & 4 & 0.5 & 8.0 \\
\hline & between $20-40 \mathrm{hrs}$ & 79 & 9.9 & 6.3 \\
\hline & between $40-50 \mathrm{hrs}$ & 292 & 36.5 & 6.4 \\
\hline & between $50-60 \mathrm{hrs}$ & 197 & 24.6 & 5.4 \\
\hline & between $60-70 \mathrm{hrs}$ & 128 & 16.0 & 5.9 \\
\hline & between $70-80 \mathrm{hrs}$ & 43 & 5.4 & 5.3 \\
\hline & $80 \mathrm{hrs}$ or more & 57 & 7.1 & 3.6 \\
\hline \multirow{7}{*}{$\begin{array}{l}\text { Number of prescribed holidays } \\
\text { per week }\end{array}$} & none & 34 & 4.3 & 4.1 \\
\hline & 1 day & 199 & 24.9 & 5.3 \\
\hline & 2 days & 524 & 65.5 & 6.1 \\
\hline & 3 days & 27 & 3.4 & 6.2 \\
\hline & 4 days & 2 & 0.3 & 2.0 \\
\hline & 5 days & 13 & 1.6 & 5.0 \\
\hline & 6 days & 1 & 0.1 & 0.0 \\
\hline & 1 place & 449 & 56.1 & 5.8 \\
\hline & 2 places & 169 & 21.1 & 6.7 \\
\hline & 3 places & 98 & 12.3 & 5.7 \\
\hline & 4 places & 45 & 5.6 & 4.5 \\
\hline Number of duty facilities in the & 5 places & 21 & 2.6 & 3.0 \\
\hline last month & 6 places & & 0.9 & 6.9 \\
\hline & 7 places & 3 & 0.4 & 4.0 \\
\hline & 8 places & 3 & 0.4 & 3.3 \\
\hline & 9 places & 0 & 0.0 & - \\
\hline & 10 places or more & $\frac{5}{30}$ & 0.6 & 2.4 \\
\hline & $\begin{array}{l}\text { National university corporation of the alma mater university } \\
\text { National corporation other than the alma mater university (including independent }\end{array}$ & 30 & 3.8 & 3.3 \\
\hline & $\begin{array}{l}\text { administrative corporations, national university corporations) } \\
\text { and Int }\end{array}$ & 43 & 5.4 & 6.7 \\
\hline & Public institution of the alma mater university & 22 & 2.8 & 5.9 \\
\hline & Public institution other than the alma mater university & 98 & 12.3 & 6.4 \\
\hline Management form (main & Public institution (Japan Red Cross, Saiseikai, etc.) & 119 & 14.9 & 5.6 \\
\hline workplace) & Social insurance related group & 15 & 1.9 & 6.5 \\
\hline & Medical corporation & 357 & 44.6 & 5.9 \\
\hline & Individual & 31 & 3.9 & 3.7 \\
\hline & Educational institution of the alma mater university & 19 & 2.4 & 5.1 \\
\hline & Educational institution other than the alma mater university & 25 & 3.1 & 5.9 \\
\hline & Other corporation or institution & 41 & 5.1 & 6.8 \\
\hline & Acute care hospital and emergency hospital & 384 & 48.0 & 5.6 \\
\hline Type of hospital (main & Acute care hospital & 111 & 13.9 & 5.6 \\
\hline workplace) & Emergency hospital & 34 & 4.3 & 4.6 \\
\hline & None of the above & 271 & 33.9 & 6.4 \\
\hline Location of the hospital (main & Located in an ordinance-designated city, or the 23 wards of Tokyo & 334 & 41.8 & 5.8 \\
\hline Location or the hospital (main & Located in a depopulated rural area & 330 & 41.3 & 5.8 \\
\hline & None of the above & 136 & 17.0 & 5.9 \\
\hline & 49 beds or less & 135 & 16.9 & 6.6 \\
\hline & $50-99$ beds & 56 & 7.0 & 5.3 \\
\hline Number of sickbeds (main & $100-299$ beds & 242 & 30.3 & 5.4 \\
\hline workplace) & $300-499$ beds & 168 & 21.0 & 5.8 \\
\hline & $500-999$ beds & 158 & 19.8 & 6.0 \\
\hline & 1000 beds or more & 41 & 5.1 & 5.4 \\
\hline
\end{tabular}




\begin{tabular}{|c|c|c|c|c|}
\hline Department (main workplace) & $\begin{array}{l}\text { internal medicine } \\
\text { cardiology } \\
\text { surgical department } \\
\text { psychiatry } \\
\text { orthopedics } \\
\text { ophtalmology } \\
\text { neurosurgery } \\
\text { ENT } \\
\text { pediatrics } \\
\text { urology } \\
\text { obstetrics and gynecology } \\
\text { dermatology } \\
\text { respiratory organs department } \\
\text { emergency department } \\
\text { gastrointestinal department } \\
\text { anesthesiology } \\
\text { radiology }\end{array}$ & $\begin{array}{r}243 \\
35 \\
94 \\
49 \\
67 \\
25 \\
26 \\
20 \\
37 \\
22 \\
31 \\
18 \\
10 \\
15 \\
25 \\
50 \\
33 \\
\end{array}$ & \begin{tabular}{r|}
30.4 \\
4.4 \\
11.8 \\
6.1 \\
8.4 \\
3.1 \\
3.3 \\
2.5 \\
4.6 \\
2.8 \\
3.9 \\
2.3 \\
1.3 \\
1.9 \\
3.1 \\
6.3 \\
4.1 \\
\end{tabular} & $\begin{array}{l}6.3 \\
6.6 \\
4.7 \\
4.9 \\
6.4 \\
7.0 \\
4.1 \\
5.7 \\
7.1 \\
5.5 \\
3.0 \\
7.3 \\
7.7 \\
7.3 \\
4.3 \\
5.8 \\
6.1 \\
\end{array}$ \\
\hline $\begin{array}{c}\text { Number of years experience as a } \\
\text { doctor }\end{array}$ & \begin{tabular}{|l} 
ess than 1 year \\
between $1-3$ years \\
between $3-5$ years \\
between $5-10$ years \\
between $10-15$ years \\
15 years ore more \\
\end{tabular} & \begin{tabular}{r|}
7 \\
11 \\
18 \\
56 \\
106 \\
602 \\
\end{tabular} & \begin{tabular}{r|}
0.9 \\
1.4 \\
2.3 \\
7.0 \\
13.3 \\
75.3 \\
\end{tabular} & $\begin{array}{l}0.9 \\
6.5 \\
5.4 \\
4.8 \\
5.5 \\
6.0 \\
\end{array}$ \\
\hline $\begin{array}{c}\text { Number of years of service (main } \\
\text { workplace) }\end{array}$ & $\begin{array}{l}\text { less than } 1 \text { year } \\
\text { between } 1-3 \text { years } \\
\text { between } 3-5 \text { years } \\
\text { between } 5-10 \text { years } \\
\text { between } 10-15 \text { years } \\
15 \text { years ore more } \\
\end{array}$ & \begin{tabular}{r|}
73 \\
140 \\
100 \\
214 \\
114 \\
159 \\
\end{tabular} & \begin{tabular}{r|}
9.1 \\
17.5 \\
12.5 \\
26.8 \\
14.3 \\
19.9 \\
\end{tabular} & $\begin{array}{l}4.7 \\
4.7 \\
5.9 \\
6.2 \\
6.4 \\
6.5 \\
\end{array}$ \\
\hline Position (main workplace) & $\begin{array}{l}\text { Medical intern (until } 2 \text { years after graduation) } \\
\text { Medical staff, medical officer, resident (after } 3 \text { rd year after graduation) } \\
\text { Assistant proffessor } \\
\text { Head physician, lecturer, head of medical office } \\
\text { Head of section, head of department, deputy head of department, proffessor, } \\
\text { associate proffessor } \\
\text { Director, vice chief director, assistant director, assistant facility director } \\
\text { Other }\end{array}$ & \begin{tabular}{r|r|r}
52 & \\
34 & \\
159 & \\
257 & \\
154 & \\
36 &
\end{tabular} & \begin{tabular}{r|r|r}
1.0 \\
19.0 \\
4.3 \\
19.9 \\
32.1 \\
19.3 \\
4.5
\end{tabular} & $\begin{array}{l}1.9 \\
5.5 \\
5.5 \\
5.7 \\
6.3 \\
5.6 \\
6.4\end{array}$ \\
\hline $\begin{array}{c}\text { Number of days of annual leave } \\
\text { taken (main workplace) }\end{array}$ & \begin{tabular}{|l|}
0 days \\
$1-3$ days \\
$4-6$ days \\
$7-10$ days \\
$11-15$ days \\
$16-19$ days \\
20 days or more \\
\end{tabular} & $\begin{array}{r}196 \\
130 \\
180 \\
190 \\
57 \\
8 \\
39 \\
\end{array}$ & \begin{tabular}{r|}
24.5 \\
16.3 \\
22.5 \\
23.8 \\
7.1 \\
1.0 \\
4.9 \\
\end{tabular} & - \\
\hline $\begin{array}{l}\text { Number of annual leave days } \\
\text { given (main workplace) }\end{array}$ & \begin{tabular}{|l|}
0 days \\
$1-5$ days \\
$6-10$ days \\
$11-15$ days \\
$16-20$ days \\
21 days or more \\
\end{tabular} & \begin{tabular}{r|}
301 \\
65 \\
110 \\
44 \\
223 \\
57 \\
\end{tabular} & $\begin{array}{r}37.6 \\
8.1 \\
13.8 \\
5.5 \\
27.9 \\
7.1 \\
\end{array}$ & $\begin{array}{l}3.9 \\
4.9 \\
5.4 \\
7.7 \\
8.1 \\
7.8 \\
\end{array}$ \\
\hline $\begin{array}{l}\text { Method of taking annual paid } \\
\text { leave (main workplace) }\end{array}$ & $\begin{array}{l}\text { work sharing method } \\
\text { circulating method } \\
\text { reverse circulating method } \\
\text { self-pay system (preceding) } \\
\text { self-pay system (at a later date) } \\
\text { self-pay system (home-work) }\end{array}$ & \begin{tabular}{r|}
439 \\
23 \\
57 \\
178 \\
64 \\
39
\end{tabular} & \begin{tabular}{r|r|}
54.9 \\
2.9 \\
7.1 \\
22.3 \\
8.0 \\
4.9
\end{tabular} & $\begin{array}{l}6.0 \\
5.9 \\
6.0 \\
6.2 \\
5.5 \\
2.3\end{array}$ \\
\hline $\begin{array}{l}\text { Related to the medical service } \\
\text { (MA) (main workplace) }\end{array}$ & $\begin{array}{l}\text { Lack of doctors at workplace } \\
\text { Lack of compliance with the labor-related laws and regulations of the hospitals } \\
\text { There is no labor union } \\
\text { The hospital is not aware of the number of working hours } \\
\text { Workload management is not conducted in matching with the number of the } \\
\text { personnel } \\
\text { There are no supervisors orcolleagues to talk to when you have trouble in your work } \\
\text { The lack of learning opportunities about advanced medical technology } \\
\text { Electronic medical records aren't implemented } \\
\text { Information is not shared } \\
\text { Your own fatigue and health anxiety } \\
\text { Litigation risk from the patient } \\
\text { Doctor-patient relationship has become patient-centered } \\
\text { Attending physician system } \\
\text { Alternative work schedule } \\
\text { I have ambition for medical procedures } \\
\text { A sense of vocation as a doctor for patients } \\
\text { Excessive number of outpatients } \\
\text { Excessive number of inpatiens in charge of } \\
\text { People around you, such as co-workers, supervisors and subordinates are taking } \\
\text { annual leave } \\
\text { Annual leave is also dependent on the agreement with the medical office } \\
\text { Hierarchical relationships and rivalry in the medical department is affecting the } \\
\text { annual leave taking of doctors } \\
\text { There is an unwritten rule unique to doctors that young doctors can not take annual } \\
\text { leave } \\
\text { When you try to take your annual leave, if you are not there, your workplace will be } \\
\text { in trouble } \\
\text { None of the above applies to me }\end{array}$ & $\begin{array}{r}433 \\
150 \\
237 \\
94 \\
138 \\
82 \\
105 \\
168 \\
79 \\
196 \\
149 \\
69 \\
290 \\
37 \\
144 \\
202 \\
112 \\
62 \\
59 \\
42 \\
24 \\
32 \\
158 \\
82\end{array}$ & $\begin{array}{r}5.1 \\
18.8 \\
29.6 \\
11.8 \\
17.3 \\
10.3 \\
13.1 \\
21.0 \\
9.9 \\
24.5 \\
18.6 \\
8.6 \\
36.3 \\
4.6 \\
18.0 \\
25.3 \\
14.0 \\
7.8 \\
7.4 \\
5.3 \\
3.0 \\
4.0 \\
19.8 \\
10.3\end{array}$ & $\begin{array}{l}5.4 \\
5.3 \\
5.7 \\
5.6 \\
5.7 \\
5.1 \\
5.2 \\
5.8 \\
5.7 \\
5.3 \\
5.8 \\
5.1 \\
5.6 \\
8.6 \\
5.4 \\
5.6 \\
5.4 \\
6.9 \\
6.3 \\
5.1 \\
3.4 \\
2.6 \\
5.0 \\
6.5\end{array}$ \\
\hline $\begin{array}{c}\text { Last year's annual income (main } \\
\text { workplace) }\end{array}$ & $\begin{array}{l}1-5 \text { million yen } \\
5-7 \text { million yen } \\
7-10 \text { million yen } \\
10-15 \text { million yen } \\
15-20 \text { million yen } \\
20 \text { million yen or more } \\
\end{array}$ & \begin{tabular}{r|}
41 \\
38 \\
71 \\
236 \\
273 \\
141 \\
\end{tabular} & \begin{tabular}{r|}
5.1 \\
4.8 \\
8.9 \\
29.5 \\
34.1 \\
17.6 \\
\end{tabular} & $\begin{array}{l}4.7 \\
4.9 \\
5.4 \\
5.5 \\
6.2 \\
6.5 \\
\end{array}$ \\
\hline $\begin{array}{l}\text { Number of working hours per } \\
\text { week (main workplace) }\end{array}$ & $\begin{array}{l}\text { less than } 20 \mathrm{hrs} \\
\text { between } 20-40 \mathrm{hrs} \\
\text { between } 40-50 \mathrm{hrs} \\
\text { between } 50-60 \mathrm{hrs} \\
\text { between } 60-80 \mathrm{hrs} \\
\text { s0 hrs or more } \\
\end{array}$ & \begin{tabular}{r|}
9 \\
129 \\
300 \\
184 \\
138 \\
40 \\
\end{tabular} & \begin{tabular}{r|}
1.1 \\
16.1 \\
37.5 \\
23.0 \\
17.3 \\
5.0 \\
\end{tabular} & $\begin{array}{l}7.1 \\
6.5 \\
6.2 \\
5.1 \\
5.9 \\
4.1 \\
\end{array}$ \\
\hline
\end{tabular}




\section{Comments}

Above, in 6.-(1) through (6) we have seen the simple totaling results, however during the research we asked the subjects to write freely their comments "About anecdotes that happened when taking their annual leave" and "Things necessary towards improving the annual leave system". In order to easily introduce the contents of valid responses, for both questions we have divided the responses roughly into the following five categories: (1) Medical office issues, superiors and local rules, (2) manpower shortage, (3) medical demand problem and the doctor-patient relationship, (4) Actual work conditions, (5) Other, and we listed a few representative examples of the opinions. (It should be noted that, when sharing the contents of the responses below, we have corrected them only if there was a significant clerical error.)In the Results section, summarize the collected data and the analysis performed on those data relevant to the discourse that is to follow. Report the data in sufficient detail to justify your conclusions. Mention all relevant results, including those that run counter to expectation; be sure to include small effect sizes (or statistically nonsignificant findings) when theory predicts large (or statistically significant) ones. Do not hide uncomfortable results by omission. Do not include individual scores or raw data with the exception, for example, of single-case designs or illustrative examples. In the spirit of data sharing (encouraged by APA and other professional associations and sometimes required by funding agencies), raw data, including study characteristics and indivldual effect sizes used in a meta -analysis, can be made available on supplemental online archives.

\subsection{Anecdotes regarding the annual leave}

(1) Medical office issues, superiors and local rules and customs

-At my previous workplace, I requested a day off in order to be able to go to my child's 3-year-old medical checkup, and it has been rejected by my boss. In that one year I have nor left work early even once because my child had fever or any such thing, so I was really sad that I didn't get even a half day off. In the end, for the one year I have worked in that workplace, I have not received even one day of leave. (Male, 50's, anesthesiology)

- I felt angry and amazed by the lack of understanding of the doctor who is taking a vacation when, during vacation, I have been contacted by a nurse to treat a hospitalized patient. I think it's obvious that you should ask for support to other physicians when in the physician in charge is on vacation. (Male, 40s, internal medicine)

- At my current workplace it is easy to take annual leave since my boss is also taking annual leave. (Male, 30's, surgery)

- Since the chairman said in front of the residents that a doctor has no rest, I feel there is no understanding of the annual paid leave for residents. (Male, 20 years old, pediatrics)

-It was not at my current workplace, but it has happened that my boss called me during my summer vacation and I had to interrupt my holiday and work for 16 hours. (Male, 40s, surgical department)

-After leaving the medical office I have taken my first annual leave. It was the first time I knew that there was such a system. Although I think I was too busy to have taken a leave anyway. (Female, 40s, internal medicine)

(2) Manpower shortage

-If I would be off, there would be no one to do surgery instead of me. (Male, 40s, surgical department)

- Since it is difficult to adjust the work, I basically cannot take any days off. I was scolded for working when my father died, and yet they could not share the work so I can take a day off. (Female, 30s, internal medicine)

-Since has become possible to receive the support of doctors of other facilities when taking leave, finally I have been able to take my annual leave. (Male, 60s, radiology)

-Since there is a doctor's assistant, it is easy to take days off. (Male, 30s, internal medicine)

- Manpower increased, it became easy to take the annual leave, everyone is happy. The virtuous cycle when manpower is increased, work becomes easier and more people come in. All of us work towards not allowing this virtuous cycle to stop. (Male, 40s, anesthesiology)

-It is easy to take leave when there are colleagues with the same specialization. (Male, 50s, orthopedic)

(3) Medical demand problem and the doctor-patient relationship

- I canceled my summer vacation family trip when the patient's condition suddenly became bad. (Male, 50s, orthopedic)

-It is good if you go far away for your annual leave, but if you are nearby, you get called in for things like emergency surgery and such. But then it stops being a vacation! (Male, 40s, anesthesiology)

-Generally, trouble occurs to the patients in charge when I take annual leave. (Male, 40s, psychiatric department)

-It is hard to take annual leave, because then I have to close the clinic. (Female, 40s, ENT) 
- I get called back to Kyushu from Kanto if the condition of the patient worsens, even during my annual leave. (Male, 60s, surgical department)

(4) Actual work conditions

- I was forced to cancel my planned vacation because the condition of the patient worsened. (Female, 40's, surgical department)

- My annual leave is devoted to participation in academic conferences. (Male, 50s, neurosurgery)

-In the hospital where I worked previously, they did not tell me how many days I can take for my annual leave. In the hospital I currently work in, every year in April we are informed about the number of carryover days from last year and the number of holidays we can take this year. After I changed jobs to the current hospital, I take a vacation every year about 10 days and travel with my family. (Male, 40s, surgical department)

- I am doing research, but it is not recognized by the hospital. I have no choice but to rely on annual leave for my research days. (Female, 40s, internal medicine)

-Even during vacation, I get work-related calls as usual. (Male, 40s, surgical department)

(5) Other

-When I was working at a hospital, I could only take a day off when I had threatened premature labor. Currently, at this medical institution, we have an application system for two months in advance, they make our schedule so that we can surely take our annual leave, it has been a big help. (Female, 30's, ENT)

- There is nothing to comment because I cannot take my annual leave. If I must say something, I was told by our director "For the Obon vacation, the one who goes first, takes it, I will take it first, so you will be on duty", so for Obon vacation I was on duty for 3 days consecutively. (Male, 40s, psychiatric department)In Table 1, we will first take a look at the actual number of annual leave days taken in the period of one year last year at the main workplace. The average number of annual leave days taken by the respondents is 5.8 days and the breakdown is as follows: the highest percentage is "0 days" with $24.5 \%$, followed by "7 to 10 days" (23.8 percent), " 4 to 6 days" (22.5\%), and "1 to 3 days" (16.3\%), over $40 \%$ (40.8\%) have answered with "3 days or less" (the sum of responses from "0 days" and "1 to 3 days"). Those who responded with "11 days or more" (the sum of "11 to 15 days", "16 to 19 days", "20 days or more") is $13.0 \%$, those who responded with "16 days or more" ( the sum of "16 to 19 days" and "20 days or more."), is 5.9\%. People who got "20 days or more" of annual leave is $4.9 \%$ of the total (Figure 1).

\subsection{Things necessary towards improving the annual leave system}

(1)Medical office issues, superiors and local rules and customs

-The boss should also take willingly their annual leave. (Female, 30's, anesthesiology)

-The climate of understanding of taking the annual leave and lack of personnel. (Male, 40s, psychiatric)

-An atmosphere at the medical office where it is easy to take annual leave. (Male, 60's, internal medicine)

-It is taken for granted that hospital doctors do not take days off. By the general society as well. (Male, 40's, surgical department)

-It is decided by the boss' consideration how many days will you be forced to take. (Female, 30s, internal medicine)

-First, fix the paid leave. Then make people take it in order. Make a doctor's union for each hospital unit. Eliminate the custom of seniority-based wages unique to the medical society. (Female, 40's, psychiatric)

(2) Manpower shortage

-Completion of the doctor's assistance system. (Male, 50s, orthopedic)

- Ensure the number of doctors is suitable to the business volume, the introduction of the shift system, the expansion of businesses supporting physicians, the reduction and increased efficiency of meetings. (Male, 50 years old, pediatrics)

-A system should be established to allocate duties from outside and based on planned annual leave to other doctors, our everyday work should be so that it allows us to not mind even if our duty is increased by the annual leave of the other Dr. (Female, 40s, internal medicine)

-Look for doctors who are able to work in shifts. (Male, 50s, ophthalmology)

-Attending physician group system, rule that all doctors properly take vacation. Ensure a number of doctors who can be together responsible for the patients of a ward other than the attending physician on a regular basis. (Female, 30s, orthopedic) 
- More than one doctor is needed for a department. In general internal medicine it is possible to substitute from other departments, but support from other departments in the palliative care department cannot be expected. (Male, 50s, internal medicine)

(3) Medical demand problem and the doctor-patient relationship

-By communicating with the outpatients, we want a structure where it is easy to be substituted by the doctor's assistant physician. (Male, 40s, internal medicine)

- Understanding from patients and staff regarding closing the clinic for vacation. (Male, 40s, pediatrics)

- Understanding from patients and their families regarding the doctor's assistant. (Female, 50s, dermatology)

-To relinquish the responsibility, to divide it. (Male, 50s, urology)

- To change the attitude of patients that says that they should be treated by the attending physician by matter of course. (Male, 40s, Gastroenterology)

(4) Actual work conditions

- Increase in the number of doctors, increase in wages. (Male, 50s, obstetrics-gynecology)

-Everyone tries to take their leave so as to avoid impediments to the business, but it is impossible not to disturb it. While it would be ideal to rest whenever you wish to, it is difficult to balance it with other departments. Therefore, I wonder if we could increase the number of holidays or have a large number of staff take their holiday all at once at the same time. (Male, 40s, anesthesiology)

-We should devise arrangements when to others can undertake the sharing of patient management. However, because of the attending physician system it could reduce business, virtually it is difficult. (Male, 60s, surgery)

-A mechanism is necessary to be able to share the burden of work. It is difficult to get a day off because even if you do, before and after your day off, you have to do most of the work of that period on your own. (Male, 50s, orthopedic)

(5)Other

- Make a union of doctors. (Female, 50s, psychiatric)

- Compliance with the Labor Standards Law at the workplace (Male, 50s, internal medicine)

- Proper placement of physicians. Doctors are concentrated in departments where the QOML(Note 6) is, such as dermatology and radiology, the essence of the problem is that the doctors are concentrated in large cities, they should be distributed even if by force. Increasing the capacity of the School of Medicine is completely meaningless, it has the opposite effect, it rather accelerates this trend. (Male, 50s, internal medicine)

-To rest without hesitation, with a recognition that "Resting is a part of working." Awareness is needed to the fact that by enjoying leisure, it increases the efficiency of work. (Female, 40s, internal medicine)

-It should be obligatory to take a certain amount of annual leave. Since there are male physicians above 50 years who sometimes prefer to spend more time at the hospital without taking the annual leave since at such age they travel less with their family. (Female, 30s, internal medicine)

- As long as the structure of exploitation by management clans and managers who believe that profit is above all, is not modified, the working environment will remain unchanged. (Male, 40s, psychiatric)

\section{Summary}

We have seen the reality of the annual leave of physicians in a simple totaling result (including comments), the following features can be pointed out.

(1) According to the findings of "Survey on the acquisition of annual paid leave" (2011) by the Japan Institute for Labor Policy and Training regarding the general workers of Japan, about half of the workers take annual leave of 6 days or more per year. In contrast, according to our research, the annual paid leave days at the main workplace of physicians, " 4 to 6 days" is the highest percentage with $25.8 \%$, followed by " 1 to 3 days" which is $24.9 \%, 22.3 \%$ are taking 0 days, if we consolidate the number of annual leave days to 6 days or less, it is applicable to more than $70 \%$ of doctors, we can see how doctors cannot (do not) take their annual leave. (Note 7)

(2) The disparity in number of days of annual leave take is present according to physicians' gender, age, physicians years of experience, affiliation to the medical office, annual income, working hours, working at acute care hospitals or an emergency hospital, number of beds in the facility where they work. However, the tendencies are varied.

(3) In particular departments (in particular specialized surgical departments), the number of leave days taken is especially low. 
(4) In the annual leave system where there is no substitute for the doctor, they either cannot take longer vacations or the number of days taken are very small.

(5) If the employer is the physician's alma mater, the number of days taken for annual leave is less. The classroom is, from a sociological point of view, a "home (family)", the professor is the patriarch, classmates graduating from the same university are like relatives or family members, if people from other universities joined the same medical office, they stand in a position corresponding to non-relatives (Nakano 1996). Therefore, it is likely that it is difficult for the so-called relatives to take annual leave.

Although we found as basic data the simple totaling result above, in order to actually highlight the complex context of how annual leave is taken, it would be necessary to observe the influence of individual factors, while other conditions are fixed. Therefore, in another paper, through verifying quantitatively by positive analysis the influence of individual factors, we would like to find clues that can help us promote the annual paid leave

\section{References}

Boulis, A. (2004). The Evolution of Gender and Motherhood in Contemporary Medicine ANALIS of the American of Political and Social Science, 596(1), 172-206.

Boulis, A., \& Jacobs, J. (2008). The Changing Face of Medicine: Women Doctors and the Evolution of Health Care in America (The Culture and Politics of Health Care Work). Cornell University Press, New York.

Igusa, G. (2013). Factors affecting young doctors to not take annual paid leave. Journal of Labor Sociology, 14, 105-132.

Japan Institute for Labour Policy and Training. (2011). Results of Survey on Paid Holiday Acquisition.

Japan Institute for Labour Policy and Training. (2012). Survey on Work Conditions and Awareness of Hospital Physicians.

Nakamura, M. (2010). Factors for female physicians to choose their specialization - Results of an interview survey. Journal of Labor Sociology, 11, 37-61.

Nakano, S. (1996). New World of Physicians - A Sociological Analysis. Keiso Shobo, Tokyo.

\section{Notes}

Note 1. Originally, it would have been desirable to do the random sampling based on the "Survey of doctors, dentists and pharmacists in 2008" by the Ministry of Health, Labor and Welfare, stratified according to the distribution of facilities and departments, but since the number of the monitors held by the private research company was limited, and by stratifying there was a risk that we may not reach the target sample size, the randomization based on stratification was abandoned.

Note 2. Rakuten Research Corporation" is a market research firm, which also holds monitor of health care workers. Survey monitor registered 2.3 million people total (as of May 1, 2015).

Note 3. The gender proportion of the survey respondents is $89 \%$ male, $11 \%$ female. The number of physician gender ratio in the large-scale survey conducted by the Japan Institute for Labor Policy and Training "Survey on employment realities of working physicians and their awareness" (2012) was $90 \%$ men, $10 \%$ female as well, about the same gender proportions as the ones of the respondents to this survey. In addition, since the ratio is limited to hospital physicians, the female ratio in this study is lower than that of the statistical population.

Note 4. Considering the page space, the original survey questionnaire will be omitted, for the questionnaire items see Table 1.

Note 5. Alma mater universities are divided into private and public, according to ranking, classified into high rank and lower rank.

Note 6. QOML is an abbreviation of Quality of My Life / Medical staffs' Life, it is derived from Quality of Life.

Note 7. Although we did not have a question in the present study asking the number of days of paid leave outside the main place of work, from qualitative research so far it is difficult to think that doctors would take their annual leave from outside their main workplace. For more information see Igusa (2013).

\section{(cc) EY}

This work is licensed under a Creative Commons Attribution 3.0 License. 